\title{
RANCANGAN SISTEM OTOMATIS START DAN MONITORING AIR HANDLING UNIT TERMINAL 2 BANDAR UDARA INTERNASIONAL SOEKARNO - HATTA
}

\author{
Muhammad Fahri ${ }^{(1)}$, KGS. M. Ismail ${ }^{(2)}$, Oka Fatra ${ }^{(3)}$ \\ 1,2,3 Politeknik Penerbangan Indonesia Curug \\ e-mail: ${ }^{(1)}$ fahri@gmail.com, ${ }^{(2)} \mathrm{kgs} . i s m a i l @$ ppicurug.ac.id, ${ }^{(3)}$ oka.fatra@ppicurug.ac.id
}

Abstrak: Terminal 2 Bandara Internasional Soekarno Hatta memiliki 97 Air Handling Unit (AHU) yang digunakan untuk mengkondisikan suhu ruangan. Ketika terjadi pemutusan atau gangguan pada aliran listrik, semua AHU tersebut harus dihidupkan dengan cara mendatangi unit tersebut. Rancangan otomatis start dan monitoring menggunakan PLC didukung oleh program visual basic diharapkan dapat membantu efektifitas operasional AHU. Rancangan ini memiliki koneksi antar PLC dan PC menggunakan wifi, dimana fungsi monitoring ketika pengoperasian unit AHU akan ditampilkan pada monitor dan fungsi kontrol pengoperasian unit AHU dapat dilakukan dari jarak jauh, serta dilengkapi dengan sistem otomatis start yaitu, ketika suplai listrik terputus dan tersambung kembali, AHU dapat langsung beroperasi tanpa mengaktifkannya secara manual.

Kata Kunci: $A H U, P L C$, Visual Studio.

Abstract: $\quad$ Terminal 2 of Soekarno-Hatta has 97 Air Handling Units (AHU) which are used to condition room temperature. When there is a disconnection or interruption to the power supply, all AHUs must be turned on by visiting the unit. The automatic start and monitoring design using PLC supported by a visual basic program is expected to help the operational effectiveness of AHU. This design has a connection between PLC and PC using wifi, where the monitoring function when operating the AHU unit will be displayed on the monitor and the control function of the AHU unit operation can be done remotely, and is equipped with an automatic start system, namely, when the power supply is cut off and reconnected, AHU can operate immediately without manually activating it.

Keyword: $\quad A H U, P L C$, Visual Studio.

http://journal.ppicurug.ac.id/index.php/jurnal-langit-biru 
Rancangan Sistem Otomatis Start dan Monitoring Air Handling Unit Terminal 2 Bandar Udara Internasional Soekarno - Hatta

\section{PENDAHULUAN}

Terminal 2 Bandara SoekarnoHatta memiliki tiga sub terminal, yaitu Terminal 2D yang melayani penerbangan Internasional, Terminal 2E yang juga melayani penerbangan Internasional, dan Terminal $2 \mathrm{~F}$ yang melayani penerbangan domestik. Dengan luas bangunan mencapai $564.000 \mathrm{~m} 2$, dimana masing-masing sub terminal terdapat lokasi boarding lounge atau ruang tunnggu yang digunakan oleh penumpang untuk menunggu jadwal penerbangan. Untuk memberikan kenyamanan calon penumpang pesawat udara yang akan berangkat, maka disetiap ruangan di dalam bandara, khususnya terminal 2 , dipasang sistem pengondisian udara yang lebih dikenal dengan Air Conditioner (AC). Bermacam-macam jenis AC yang digunakan, diantaranya adalah sistem AC Sentral, AC Split, AC Split Duct, dan AC Roof Top. Diantara sistem yang disebutkan diatas, sistem yang paling banyak digunakan untuk mengondisikan suhu ruangan terminal 2 adalah tipe AC sentral, karena sistem ini memiliki kapasitas yang besar untuk mendinginkan ruangan yang luas.

AC Sentral terdiri dari beberapa bagian, diantaranya Chiller. Chiller adalah sistem induk dari sebuah AC Sentral, karena di dalem sistem Chiller terdapat kompresor yang merupakn "jantung" dari sebuah AC, kemudian ada kondensor, valve eksvansi, kondensor, dan lain-lain. Bagian lain dari AC sentral adalah Air Handling Unit FCU (AHU) dan Fan Coil Unit (FCU). Berdasarkan sistem dan kegunaannya, antara AHU dan FCU adalah sama. Keduanya samasama mendapat supalai air dingin dari Chiller dan keduanya sama-sama berfungsi untuk mendinginkan ruangan. Hanya saja perbedaannya terletak pada kapasitasnya, dimana AHU memiliki kapasitas lebih besar daripada FCU.

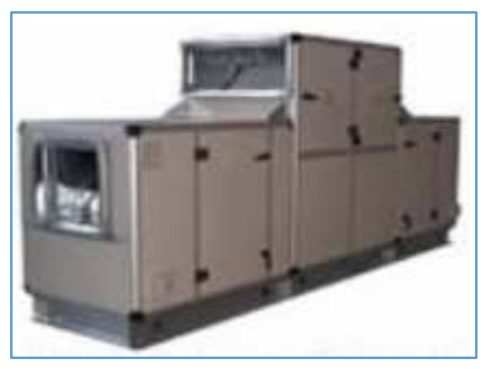

(a)

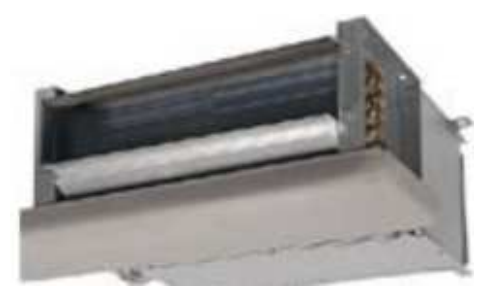

(b)

Gambar 1. AHU (a) FCU (b)

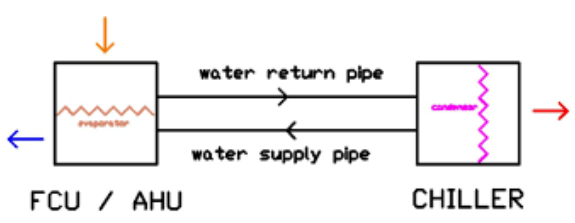

Gambar 2. Sirkulasi AC Sentral

Pada terminal 2 terdapat AHU, yang terdiri dari beberapa merk, yaitu ciat, hitachi, itu-york, dan dunhambush. Dari beberapa merk tersebut sistem kerja penyuplaiannya hampir sama Masih dioperasikan secara manual, dimana terdapat perbedaan antar AHU merk CIAT dengan yang lainnya. Perbedaan AHU merk CIAT terdapat pada sistem kontrolnya, dimana AHU merk CIAT sudah di modifikasi dengan 
menggunakan Inverter agar dapat di kontrol jarak jauh melalui monitor di ruangan teknisi. Penulis menggunakan AHU merk DUNHAMBUSH dalam permasalahan ini bedasarkan data yang diperoleh. Pada Terminal 2 terdapat 8 unit AHU Merk Dunhambush, dengan lokasi AHU yaitu 4 unit di Terminal 2E dan 4 unit di terminal $2 \mathrm{~F}$, masingmasing unit AHU dikontrol oleh satu buah panel kontrol.

Pada saat ini, sistem kontrol yang terdapat pada panel kontrol AHU Dunhambush ini tidak memiliki sistem yang dapat me-reset kembali operasional sistem AHU apabila suplai listrik terputus dan tersambung kembali. Teknisi harus datang ke unit AHU untuk me-reset sistem AHU agar unit beroperasi kembali, sementara peralatan yang harus di-reset jumlahnya banyak. Hal ini dapat mengganggu kenyamanan calon penumpang pesawat udara yang akan lepas landas dan penumpang pesawat udara yang baru saja mendarat, karena apabila unit AHU tidak beroperasi, maka temperatur sebagian ruangan di Terminal 2 Bandara Soekarno-Hatta akan meningkat. Tidak hanya penumpang saja, temperatur kantor staf karyawan maskapai penerbangan dan tenant yang udara dinginnya disuplai oleh AHU Dunhambush akan meningkat. Tentu saja hal ini akan merugikan banyak pihak, khusunya adalah PT. Angkasa Pura II (Persero) sebagai pengelola bandara. penelitian ini akan difokuskan pada usaha bagaimana merancang sistem auto-start dan monitoring pada AHU Merk Dunhambush menggunakan Programmable Logic Controller (PLC) dibantu tampilan pada monitor komputer oleh software Visual Basic.

\section{LANDASAN TEORI AC Sentral}

Handoko (2008), menjelaskan bahwa sistem Central Air Conditioning System (Sistem Pengkondisian Udara secara sentral), yang biasa dirancang pada bangunan dapat dijelaskan sebagai berikut : Unit pendingin utama digunakan 2 unit Water Cooled Water Chiller dimana satu unit beroperasi dan satu unit sebagai cadangan, unit Chiller beroperasi dengan menggunakan "Primary Refrigerant" berupa refrigerant R123 pada unit Chiller \& R 134A pada unit purging yang sudah ramah lingkungan, nantinya akan mendinginkan

"Secondary Refrigerant" berupa air, dimana air yang sudah didinginkan ini di sirkulasikan oleh Chilled Water Pump ke AHU dan FCU.

\section{Air Handling Unit (AHU)}

Handoko (2008), menyampaikan komponen Air Handling Unit (AHU) adalah suatu peralatan atau mesin yang dapat mengubah suhu udara panas menjadi dingin sesuai dengan standar, untuk beberapa ruang yang luas dan terpisah-pisah. AHU dirancang berdasarkan standar industri yang ketat, serta dipabrikasi dengan ketrampilan dan kualitas yang tinggi. AHU dibuat sebagai bagian dari Pengkondisian Udara yang ditempatkan dekat dengan lokasi ruang yang akan diatur suhu udaranya, hasil pendinginan udara digunakan untuk menjaga suhu udara pada ruang-ruang yang di aliri udara dingin sesuai dengan yang diinginkan 
Rancangan Sistem Otomatis Start dan Monitoring Air Handling Unit Terminal 2 Bandar Udara Internasional Soekarno - Hatta

masing-masing kegunaan, juga untuk mendinginkan suhu ruangan peralatan elektonik agar peralatan tersebut usia pakainya panjang. AHU pada umumnya untuk melayani ruangan sangat luas seperti : Ruang Peralatan Elektronik, Terminal Bandara, Stasiun, Terminal Bus, Rumah Sakit, Plaza, Hotel, Gedung Pertemuan, Super Market, dan lain-lain.

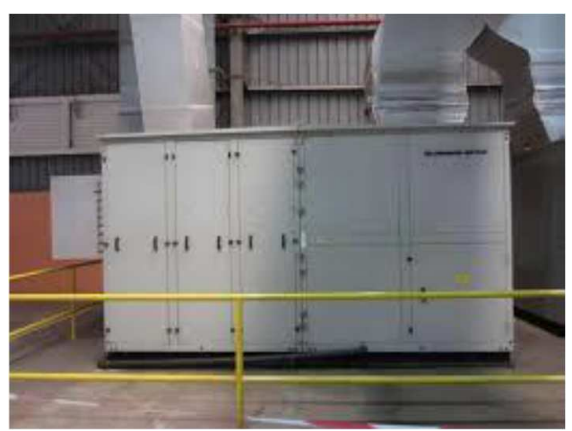

Gambar 3. Air Handling Unit

Komponen - komponen dari AHU sebernanya cukup sederhana yang terdiri dari : Casing, Koil, Air Filter dan Motor Blower.

Pada Gambar 4 dijelaskan bagaimana siklus dari system pendinginan $\mathrm{AHU}$, dimana udara luar

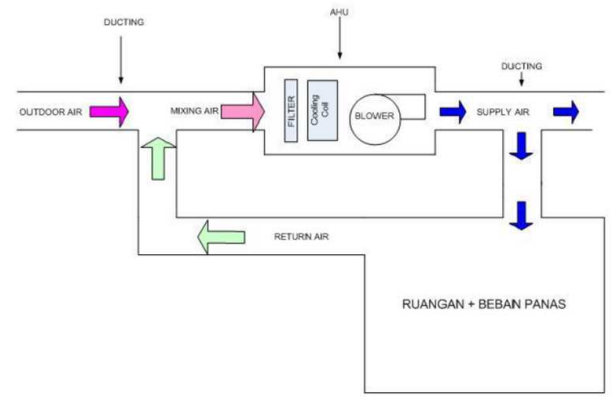

Gambar 4. Siklus Air Handling Unit

dan udara dari ruangkan bergabung dan masuk ke AHU melewati filter untuk dibersihkan dan didinginkan dengan
Cooling Coil kemudian didistribusikan oleh blower ke setiap ruangan.

\section{PLC (Programmable Logic Control)}

Said, Hanif (2012), menyampaikan bahawa dalam sistem otomatis, PLC umumnya dianggap sebagai jantung dari sistem kontrol. PLC dapat di program dengan menggunakan aplikasi kemudian di simpan dalam memori PLC. PLC juga dapat memonitoring keadaan dari sistem melalui sinyal balik dari Input yang diterima yang kemudian mengendalikan perangkat di lapangan berdasarkan Output dari PLC. Selain itu PLC juga dapat mengontrol perintah sederhana yang berulang-ulang, atau menghubungkan PLC dengan komputer melalui jaringan komunikasi untuk meningkatkan kontrol proses yang kompleks. PLC secara bahasa berarti pengontrol logika yang dapat diprogram. Dengan kata lain PLC merupakan suatu sistem peralatan yang digunakan untuk mengontrol suatu peralatan atau sistem lain menggunakan suatu rangkaian logika yang dapat diprogram sesuai kebutuhan. PLC menyerupai komputer elektronik yang mudah digunakan (user friendly) yang memiliki fungsi kendali untuk berbagai tipe dan tingkat kesulitan yang beraneka ragam.

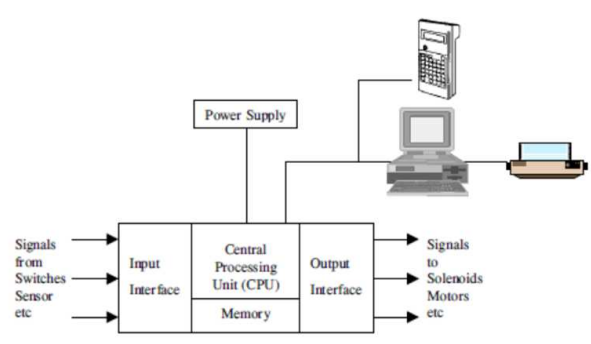

Gambar 5. Blok Diagram PLC (Sujatmoko, 2000) 
Langit Biru: Jurnal Ilmiah Aviasi Vol. 14 No. 1 Februari 2021

ISSN (p) 1979-1534 ISSN (e) 2745-8695

\section{Ladder Diagram}

$\begin{array}{rrr}\text { Micro } & \text { Control } & \text { (1999), } \\ \text { menjelaskan } & \text { Diagram } & \text { Ladder }\end{array}$
menggambarkan program dalam bentuk grafik. Diagram ini dikembangkan dari kontak-kontak relay yang terstruktur yang menggambarkan aliran arus listrik. Dalam diagram ladder terdapat dua buah garis vertikal dimana garis vertikal sebelah kiri dihubungkan dengan sumber tegangan positif catu daya dan garis sebelah kanan dihubungkan dengan sumber tegangan negatif catu daya. Program ladder ditulis menggunakan bentuk pictorial atau symbol yang secara umum mirip dengan rangkaian kontrol relay. Program ditampilkan pada layar dengan elemenelemen seperti normally open contact, normally closed contact, timer, counter, sequencer dll ditampilkan seperti dalam bentuk pictorial. Ladder Diagram tersusun dari dua garis vertikal yang mewakili rel daya. Di antaragaris vertikal tersebut disusun garis horizontal yang disebut rung (anak tangga) yang berfungsi untuk menempatkan komponen kontrol sistem.

\section{Visual Basic}

Basuki, Rahmat (2006), menjelaskan Bahasa Basic pada dasarnya adalah bahasa yang mudah dimengerti sehingga pemrograman di dalam bahasa Basic dapat dengan mudah dilakukan meskipun oleh orang yang baru belajar membuat program. Hal ini lebih mudah lagi setelah hadirnya Microsoft Visual Studio, yang dibangun dari ide untuk membuat bahasa yang sederhana dan mudah dalam pembuatan scriptnya (simple scripting language) untuk graphic user interface yang dikembangkan dalam sistem operasi Microsoft Windows.

Visual Basic merupakan bahasa pemrograman yang sangat mudah dipelajari, dengan teknik pemrograman visual yang memungkinkan penggunanya untuk berkreasi lebih baik dalam menghasilkan suatu program aplikasi. Ini terlihat dari dasar pembuatan dalam Visual Basic adalah FORM, dimana pengguna dapat mengatur tampilan form kemudian dijalankan dalam script yang sangat mudah.

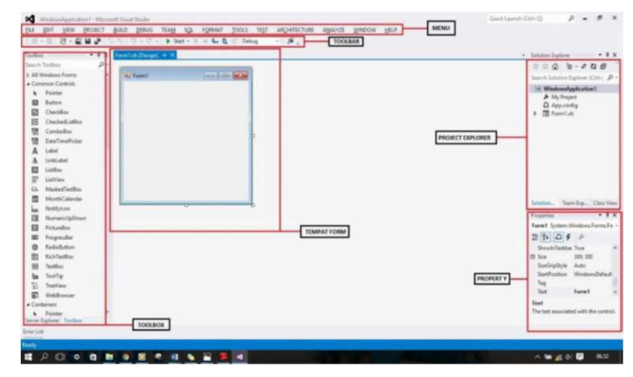

Gambar 6. Antar Muka Visual Basic

Pembuatan program aplikasi menggunakan Visual Basic dilakukan dengan membuat tampilan aplikasi pada form, kemudian diberi script program di dalam komponenkomponen yang diperlukan. Form disusun oleh komponen-komponen yang berada di [Toolbox], dan setiap komponen yang dipakai harus diatur propertinya lewat jendela [Property].

\section{METODOLOGI PERANCANGAN Desain Perancangan \\ Kondisi Saat Ini}

AHU Dunhambush yang ada di Terminal 2 Bandara Soekarno-Hatta terdiri dari 8 unit, 4 unit berada di Terminal 2E dan 4 unit berada di Terminal 2F. Masing-masing AHU 
Rancangan Sistem Otomatis Start dan Monitoring Air Handling Unit Terminal 2 Bandar Udara Internasional Soekarno - Hatta

dikontrol oleh satu buah panel kontrol. Panel kontrol ini berfungsi sebagai pengendali dari operasional AHU, dan juga sebagai proteksi pada sistem AHU. Peran AHU Dunhambush sangat dibutuhkan karena suplai udara dingin yang dihasilkan oleh AHU dialirkan ke shopping arcade dan executive lounge di Terminal 2E dan 2F. Saat ini, sistem kontrol pada AHU Dunhambush tidak menggunakan sistem otomatis Start, artinya sistem ini tidak memungkinkan kontrol AHU dapat me-reset power secara otomatis pada saat listrik tersuplai kembali. Tentu saja hal ini dapat mengganggu operasional AHU itu sendiri dan hal ini dapat berakibat pada naiknya temperatur udara di ruangan yang udara dinginnya disuplai oleh AHU Dunhambush.

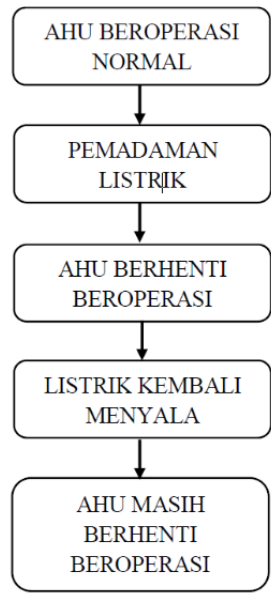

Gambar 7. Sistem Kerja saat ini

\section{Kondisi Yang Diinginkan}

Rancangan ditujukan untuk memodifikasi sistem kontrol pada AHU Dunhambush dengan cara menambahkan fungsi auto-restart ketika suplai listrik mengalami gangguan serta fungsi monitoring; flowchart dpat dilihat gambar 8:

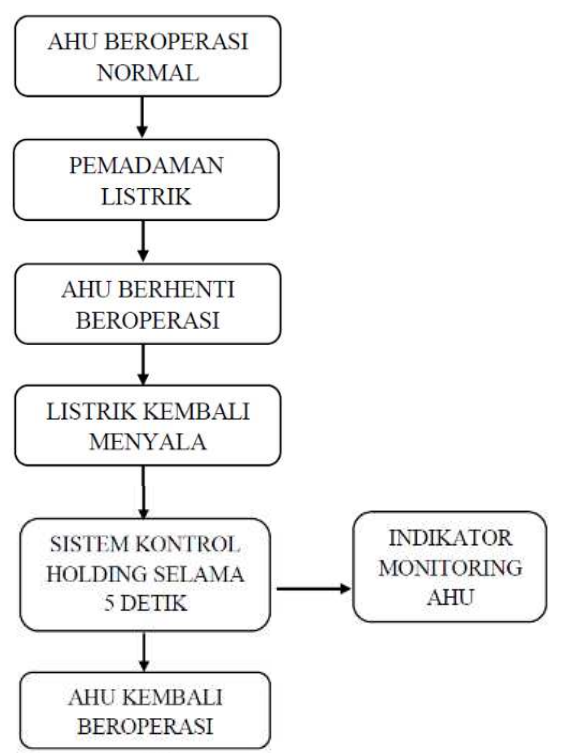

Gambar 8. Sistem Kerja yang diinginkan

\section{Kriteria Perancangan}

Penambahan sistem Otomatis start ini menggunakan komponen kontrol listrik berupa beberapa kontaktor dan timer yang terintegrasi ke dalam rangkaian kontrol sebelumnya. Alat ini juga menerapkan prinsip start holding, yaitu ketika suplai listrik dari PLN sudah nyala, maka AHU tidak langsung beroperasi. Menunggu waktu sekitar 5 detik untuk mengaktifkan rangkaian kontrol agar AHU beroperasi. Hal ini dirancang agar AHU beroperasi saat tegangan listrik telah stabil. Dan apabila terjadi masalah saat auto-restart yang mengakibatkan AHU tidak beroperasi maka pada sistem kotrol akan memberi informasi ke teknisi di ruangan melalui sistem monitoring yang pengiriman datanya menggunakan PLC dan wifi sebagai pengganti kabel. 


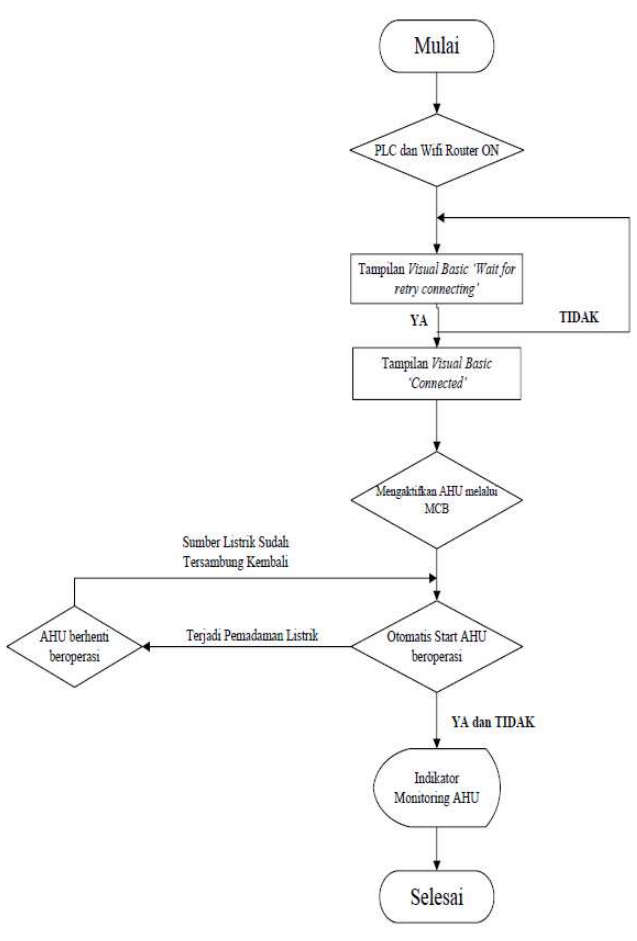

Gambar 9. Flowchart Desain Perancangan

\section{PEMBAHASAN}

\section{Gambaran Umum Rancangan}

Rancangan sistem kontrol dan monitoring AHU ini adalah

1. Sistem kontrol dan monitoring, untuk sistem ini menggunakan komponen monitor yang ditempatkan di ruang teknisi, yang dilengkapi dengan program Visual Basic sebagai media pengoperasian dan monitoring unit AHU

2. Sistem kontrol adalah pengoperasian tombol on/off yang terdapat pada monitor akan dikirim ke komponen PLC menggunakan media wifi, sehingga akan menjadi inputan PLC, kemudian PLC akan mengeluarkan output sebagai perintah unit AHU

3. Sistem monitoring merupakan pendeteksian kondisi unit AHU oleh PLC yang kemudian dikirim ke monitor pada ruang teknisi dengan menggunakan media wifi.

4. Rancangan ini dilengkapi dengan sistem auto reset, dengan cara merubah rangkaian on untuk unit AHU komponen sistem pendinginan AC Sentral yang berfungsi sebagai pendingin udara dan pendistrisbusi udara dingin ke seluruh ruangan di bandara. Sistem tata udara pada bandara termasuk beban non priority, yang artinya jika terjadi listrik padam maka sistem tata udara di bandara akan berhenti beroperasi.

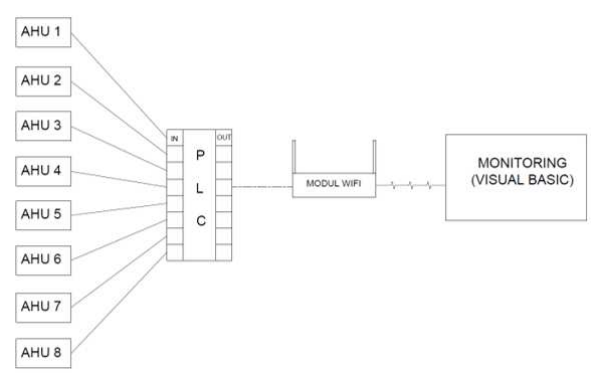

Gambar 10. Diagram Rancangan

\section{Tahapan Rancangan}

Perancangan sistem otomatis start AHU terdiri dari beberapa tahapan yaitu pemilihan komponen PLC, pemilihan komponen Wifi, perancangan wiring diagram, Pemograman Ladder Diagram, Pemograman Visual Basic.

\section{Pemilihan PLC}

Dalam rancangan ini penulis harus menentukan input dan output yang digunakan berdasarkan kebutuhan dengan penambahan ethernet port untuk disambungkan dengan modul wifi untuk mengirimkan data. Berdasarkan IDEC_Smart_AXIS_Relay_Catalog ue, didapat PLC IDEC FT1AH40RSA yang memiliki 24 input dan 16 output dengan indikator PLC mini ialah 32 sampai dengan 128 
Rancangan Sistem Otomatis Start dan Monitoring Air Handling Unit Terminal 2 Bandar Udara Internasional Soekarno - Hatta

input dan output. Rancangan ini memakai 24 input dan 0 output. PLC IDEC ini dapat melakukan ekstensi atau penambahan jumlah input maupun output. Sedangkan untuk external power supply memiliki kapasitas maksimal 24 VDC.

2. Pemilihan Wifi

Untuk memilih modul wifi yang sesuai pastikan pada modul wifi terdapat port Ethernet untuk menghubungkan PLC degan modul wifi. Berdasarkan Datasheet wifi TLWA5210G didapat kemampuan membangun koneksi dengan jarak maksimum mencapai $15 \mathrm{~km}$

3. Perancangan Wiring Diagram Rangkaian kontrol otomatis Star $t$ Air Handling Unit. Dimana pada rangkaian ini, ahu dapat kembali beroperasi apabila suplai listrik yang terputus dan tersambung kembali tanpa harus diaktifkan secara manual oleh teknisi.

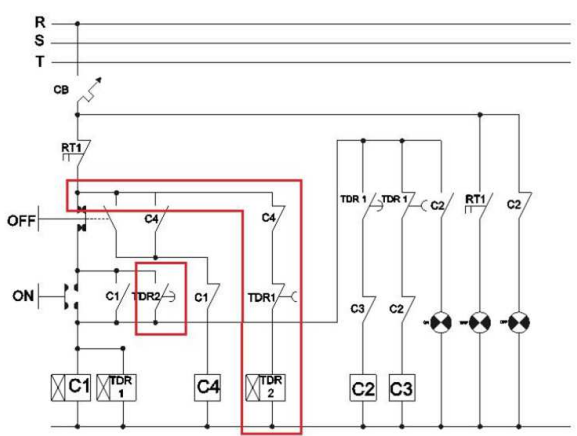

Gambar 11. Rangkaian Otomatis Start AHU

4. Pemograman Ladder Diagram

Salah satu metode pemrograman PLC yang sangat umum digunakan adalah diagram tangga (Ladder Diagram). Pada rancangan ini penulis menggunakan indikator yaitu penentuan input dan output. Kemudian langkah yang pertama adalah meng-install program PLC yang akan dipakai. WindLDR merupakan perangkat lunak produksi IDEC Corporation. WindLDR yang digunakan penulis kali ini adalah versi 7.0. Program ini dapat digunakan untuk PLC dan

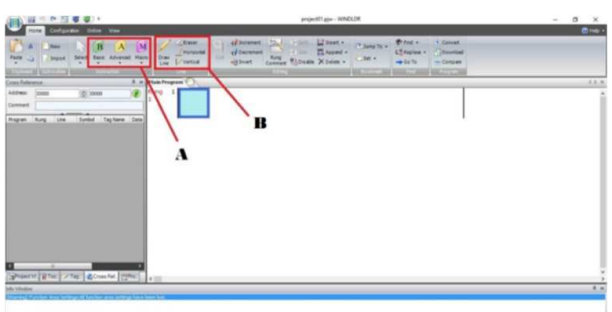

Gambar 12. Tampilan Awal WindLDR

Smart Relay merk IDEC

Pada kotak A terdapat Basic, Advanced dan Macro. Ketiga ikon diatas berfungsi sebagai kumpulan komponen dasar dalam pembuatan ladder diagram seperti kontak NO/NC, Timer, Output, dll. Pada kotak B terdapat ikon Draw Line, Vertical, Horizontal dan Eraser. Ikon-ikon tersebut memiliki fungsi sebagai penyambung antara tiap-tiap komponen (kontak NO/NC, Timer, Output, dll).

Pada kotak nomor satu (1) terdapat 'Download dan Upload'. Download berfungsi untuk memasukan ladder diagram yang dibuat ke dalam PLC. Sedangkan Upload berfungsi untuk 


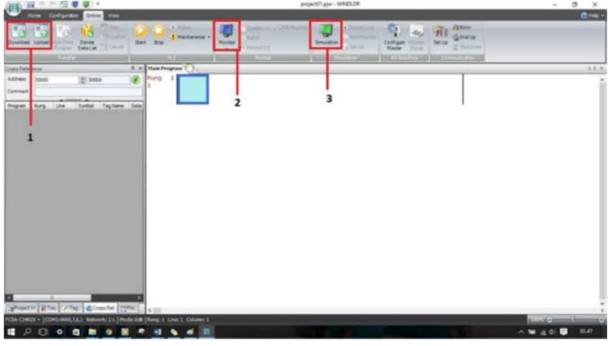

Gambar 13. Tampilan pada menu bar 'Online

memasukan ladder diagram yang berada pada PLC ke dalam software WindLDR. Pada kotak no dua (2) terdapat 'Monitor' berfungsi untuk menghubungkan ladder diagram dengan monitor. Dan pada kota ke tiga (3) terdapat 'Simul ation' berfungsi untuk mensimulasikan ladder diagram. Sehingga didapatkan hasil ladder diagram berikut

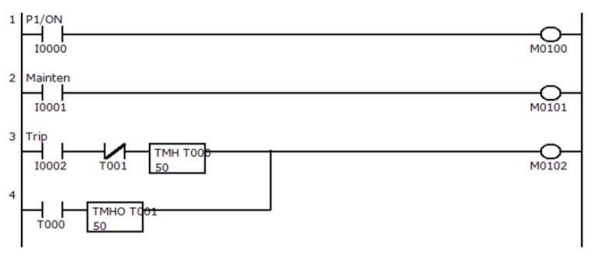

Gambar 14. Ladder Diagram Rancangan untuk AHU 1

Pada rancangan ini AHU 1 sampai dengan AHU 8 memiliki bentuk ladder diagram yang sama dengan input dan ouput yang berbeda namun memiliki fungsi yang sama juga.

5. Pemrograman Visual Basic

Pada rancangan ini penulis menggunakan Visual Basic 2012 untuk membuat sistem monitoring Air Handling Unit. Adapun tahaptahap pembuatan program sebagai berikut: a. Menjalankan Software Visual Basic 2012

b. Kemudian pilih 'New Project' dan 'Windows Forms Application' untuk memulai dan membuka halaman pembuatan program.

c. Setelah masuk ke halaman form pemrograman maka, penulis dapat melakukan pembuatan program aplikasi menggunakan Visual Basic, dengan membuat tampilan aplikasi pada form, kemudian diberi IP Adress program di dalam komponenkomponen yang diperlukan.

d. Pembuatan bahasa pemrograman seperti yang ditampilkan pada gambar berikut.

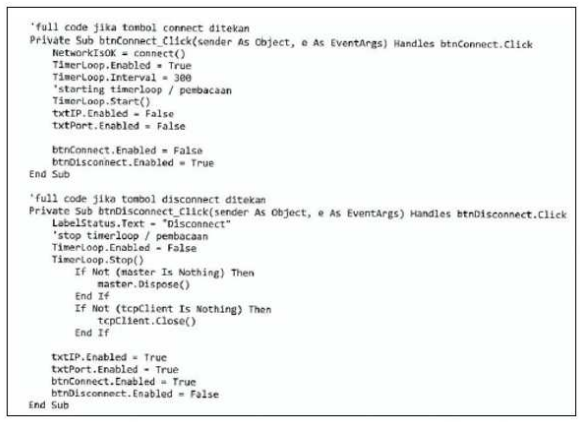

Gambar 15. Pemograman Tombol On/Off Rancangan untuk AHU 1

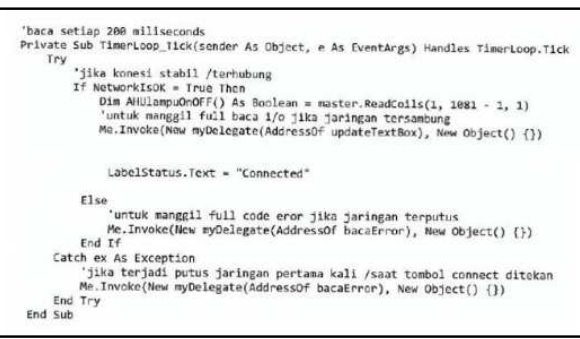

Gambar 16. Pemograman Terhubung/Terputus Rangkaian Rancangan untuk AHU 1 
Rancangan Sistem Otomatis Start dan Monitoring Air Handling Unit Terminal 2 Bandar Udara Internasional Soekarno - Hatta

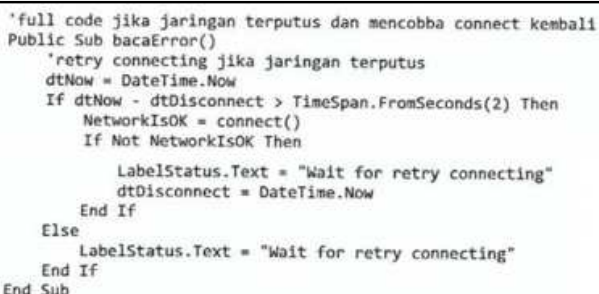

Gambar 17. Pemograman Auto Start Jika Rangkaian Terputus Rancangan untuk AHU 1

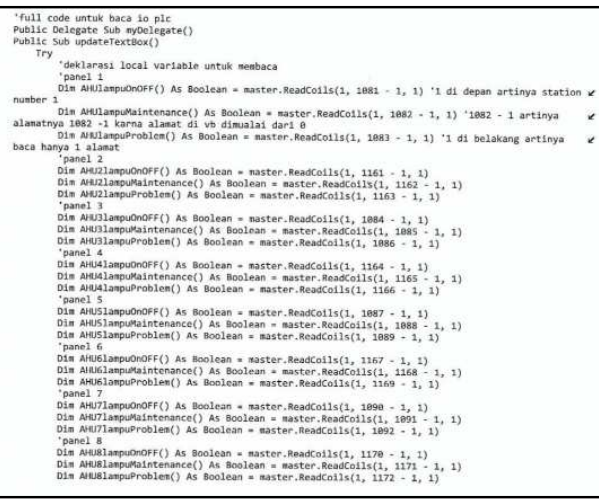

Gambar 18. Pemograman

Pembacaan Input/Ouput PLC Rancangan untuk AHU 1

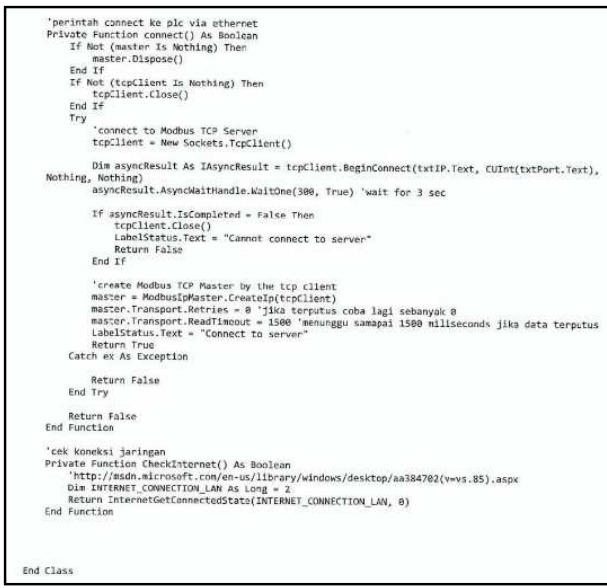

Gambar 19. Pemograman Koneksi PLC Via Ethernet

e. Setelah pemrograman dilakukan dapat di uji dengan menekan ikon START untuk memastikan apakah pemrograman yang dibuat berhasil. Jika program sesuai dengan yang diinginkan bisa disimpan

f. Jika file dibuka maka akan menghasilkan tampilan visual basic Air Handling Unit seperti beriut :

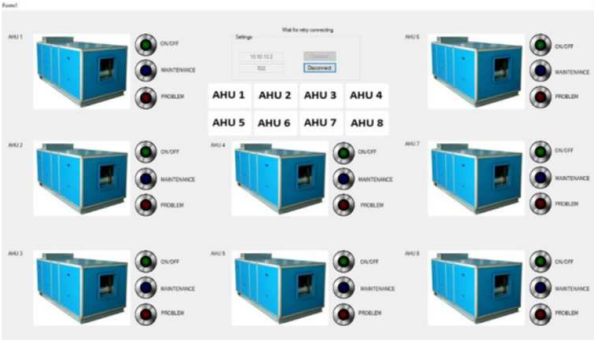

Gambar 20. Tampilan monitoring Air Handling Unit

\section{Uji Coba Rancangan}

Setelah rancangan selesai dibuat perlu diadakan uji coba rancangan pada 2 unit AHU Dunhambush yang ada di Terminal 2 Bandara Soekarno-Hatta untuk memastikan bahwa rancangan yang telah dibuat bekerja sesuai yang diinginkan. Berikut adalah pengujian yang dilakukan untuk menguji bekerjanya rancangan:

\section{Interprestasi Hasil Uji Coba Rancangan}

Hasil dari uji coba didapatkan:

a. Pada saat wifi router dan PLC di hidupkan pc dapat terhubung dengan wifi router untuk pengiriman data dari PLC ke Visual Basic tanpa harus terkoneksi dengan jaringan internet.

b. pada saat CB kontrol panel AHU di hidupkan sistem otomatis Start dapat beroperasi sampai dengan putaran motor Star dan Delta. Dengan lampu indikator menyala dan sistem 
Tabel 1. Pengujian Rancangan

\begin{tabular}{|l|c|c|l|}
\hline \multirow{2}{*}{ Kriteria } & \multicolumn{2}{|c|}{ Kesesuaian } & \multicolumn{1}{|c|}{ Keterangan } \\
\cline { 2 - 3 } & Sesuai & Tidak & \\
\hline Otomatis start & OK & & $\begin{array}{l}\text { Sistem otomatis Start dapat } \\
\text { bekerja }\end{array}$ \\
\hline $\begin{array}{l}\text { Pengujian } \\
\text { Maintenance (Push } \\
\text { button OFF ditekan) }\end{array}$ & OK & & $\begin{array}{l}\text { Memutuskan rangkaian } \\
\text { listrik dan motor }\end{array}$ \\
\hline $\begin{array}{l}\text { Pengujian Start } \\
\text { Running (Push button } \\
\text { ON ditekan) }\end{array}$ & OK & & $\begin{array}{l}\text { Menghidupkan rangkaian } \\
\text { listrik dan motor }\end{array}$ \\
\hline $\begin{array}{l}\text { Pengujian Problem } \\
\text { Oengujian Pemadaman }\end{array}$ & OK & $\begin{array}{l}\text { Memutuskan rangkaian } \\
\text { dan mematikan motor }\end{array}$ \\
\hline Listrik & OK & $\begin{array}{l}\text { AHU berhenti beroperasi } \\
\text { dan sistem otomatis Start } \\
\text { beroperasi setelah } \\
\text { mendapat suplai listrik } \\
\text { kembali }\end{array}$ \\
\hline
\end{tabular}

monitoring ON/OFF pad Visual Basic juga menyala.

c. Kemudian pada saat percobaan ON/OFF, Maintenance dan Poblem dilakukan rangkaian pada AHU dapat beroperasi dengan semestinya dan mengirimkan data ke Visual Basic dengan indikator yang sesuai.

d. Dan saat terjadi pemadaman listrik dan saat listrik sudah tersuplai kembali (simulasi) sistem otomatis Start AHU dapat beroperasi kembali dengan normal.

e. Saat percobaan pemutusan jaringan wifi dengan melepaskan kabel ethernet terkadang harus melepaskan dan memasangkan kembali kabel ethernet sampai dengan terdpat indikator 'Connected' pada Visual Basic.

\section{KESIMPULAN DAN SARAN}

\section{Kesimpulan}

Dari pembahasan uji rancangan dapat disimpulkan sebagai berikut :

1. Sistem kontrol pada rancangan dapat mengoperasikan unit AHU dapat dilakukan dari jarak jauh (ruang teknisi).

2. Rancangan ini juga sudah dapat berfungsi sebagai otomatis (reset) beroperasi kembali ketika AHU mengalami berhenti beroperasi dikarenakan pemadaman listrik.

3. Sistem monitoring pada rancangan ini dapat menampilkan informasi pengoperasian unit AHU pada monitor di ruang teknisi

\section{Saran}

Dalam perancangan sistem otomatis start AHU yang dimaksud, diperlukan saran dan pengembangan lebih lanjut guna mengoptimalkan serta memperbaiki kekurangan yang ada. Adapun saran yang dapat penulis sampaikan meliputi :

1. Melengkapi system yang sudah ada dengan penambahan sistem control, dengan memanfaatkan output PLC yang masih belum digunakan.

2. Dalam penentuan modul wifi yang digunakan dapat disarankan untuk penggunaan wifi dibekali sistem pengaman yang cukup memadai.

\section{DAFTAR PUSTAKA}

Basuki, Achmad, 2006, Algoritma Pemrograman 2 Menggunakan Visual Basic 6.0. Surabaya : Institut Teknologi Sepuluh Nopember Surabaya.

Datasheet wifi TL-WA5210G 
Rancangan Sistem Otomatis Start dan Monitoring Air Handling Unit Terminal 2 Bandar Udara Internasional Soekarno - Hatta

Handoko, Juni, 2008, Merawat \& Memperbaiki AC, Jakarta : PT Kawan Pustaka.

IDEC_Smart_AXIS_Relay_Catalogue

Micro Control, 1999, Omron Asia Pacific PTE LTD.

PT. Angkasa Pura 2, 2015, Standar Operasional Prosedur.

Said, Hanif, 2012, Aplikasi Programmable Logic Control (PLC) dan Sistem Pneumatik pada Manufaktur Industri, Yogyakarta : ANDI.

Sujatmoko, MN, 2000, Dasar-Dasar Control Component dan SYSMAC, Manufacturing Engineering PT. Omron Manufacturing of Indonesia. 